\title{
AKT3 Gene Alteration Positive
}

National Cancer Institute

\section{Source}

National Cancer Institute. AKT3 Gene Alteration Positive. NCI Thesaurus. Code C146653.

A finding indicating that mutation, overexpression or rearrangement of the AKT3 gene has been detected in a sample. 